\section{Comment}

Getting psychiatric patients to the polls is a gruelling task for administrators, clinicians, and the patients themselves. Psychiatric patients in hospital received the vote only after a protracted debate which included a series of legal test cases and a Speaker's conference on electoral reform (Gostin, 1986). During the debate fears were expressed that psychiatric patients might be unduly influenced in their voting by hospital staff, and that large numbers of patients voting in one constituency might have a distorting effect on the result.

Our findings suggest the problem is not too many but rather too few psychiatric patients voting. The process of registering for the vote is difficult for psychiatric patients. Although the patient's declaration is a relatively simple form, it is more complex than the registration form issued to householders. Patients are required to complete the declaration without assistance (unless they are physically dis- abled), and the form requires attestation by a member of the hospital staff.

It is disappointing that only $25(3 \%)$ of the patients resident at the two hospitals cast their vote in the general election of 1992. Long-term psychiatric patients are likely to suffer disabilities which seriously impair their motivation. Parliament has made provision, albeit with procedural complexities, for psychiatric patients to vote. If such patients are to vote in any significant number, administration and clinical staff must allocate resources and bring enthusiasm to the task. Other citizens exercise their own judgement in deciding whether or not to vote. How much should those responsible for the care of psychiatric patients do to ensure that their patients vote?

\section{References}

Gostin, L. (1986) Mental Health Services-Law and Practice. London: Shaw.

\title{
A survey of voting in elderly psychiatric and medical in-patients
}

\author{
ANDREW Stanners, Senior Registrar, Department of Medicine, Seacroft Hospital, \\ Leeds LS14 6UH; SuZANNE KITE, Senior House Officer, Department of Medicine for \\ the Elderly, St James University Hospital, Leeds LS9 7TF; DAvid HaRGREAVES, \\ Senior House Officer; and WENDY BURN, Consultant, Department of Psychiatry of \\ Old Age, St James University Hospital, Leeds LS9 7TF
}

The UK has recently held a general election in which the future of the National Health Service has been a major issue. The elderly constitute a growing proportion of the electorate and are frequent users of the Health Service, yet some may have been unable to vote because they are in-patients. Elderly in-patients can vote by post or proxy or by being taken to their polling station by relatives or party representatives, but for many these arrangements may be inadequate.

\section{The study}

The survey took place on three wards for the psychiatry of old age and one ward for the medicine for the elderly in two district general hospitals on the day after the general election. Voters and non-voters from each ward were identified by questioning of patients, carers, and ward staff. Patients were also asked if they would have liked to vote. Cognitive impairment was measured using the Hodkinson 10point scale (Hodkinson, 1972) and functional ability using the 20-point Barthel activities of daily living index (Mahony \& Barthel, 1965). It was also established whether the patients had relatives or carers who might have arranged a vote for them. We also documented community charge exemption and length of stay by election day (Table I).

\section{Findings}

There were 82 patients on the four wards, of whom only five voted. Two of the five voted by post or proxy and the remaining three made their own way to a polling booth. Of the 60 patients who expressed an 
TABLE I

Characteristics of voters and non-voters

\begin{tabular}{|c|c|c|}
\hline & $\begin{array}{l}\text { Voters } \\
(n=5)\end{array}$ & $\begin{array}{c}\text { Non-voters } \\
(n=77)\end{array}$ \\
\hline $\begin{array}{l}\text { Mean (s.d.) Barthel score } \\
\text { Mean (s.d.) Hodkinson score } \\
\text { Median (range) length of stay: } \\
\text { days } \\
\text { No. }(\%) \text { of carers } \\
\text { Community charge exemption } \\
(\%)\end{array}$ & $\begin{array}{c}18.8(2.2) \\
9.6(0.9) \\
23(8-47) \\
5(100)\end{array}$ & $\begin{array}{c}14.4(6.2) \\
5.9(3.8) \\
\\
27(0-1109) \\
54(70.1) \\
27(35)\end{array}$ \\
\hline
\end{tabular}

opinion, $80 \%$ wanted to vote yet only $8.3 \%$ managed to. No patients voted from the ward for medicine for the elderly. One patient was not eligible to vote on grounds of nationality. Seven patients were detained under Sections of the Mental Health Acts on election day, none of whom voted. The non-voters included four patients with psychotic illnesses who believed that they had voted, one "over the airwaves" and the other three in a sham election held on the ward.

\section{Comments}

Voting is an important freedom and one which should be protected for all hospital patients. However, our results show that a large number of our population did not vote despite expressing a desire to do so.

Some of our subjects were severely mentally impaired and would have been unable to understand the issues involved in voting. However, people with dementia may still hold strong political beliefs and although 27 of our subjects were excluded from paying the community charge on the grounds of severe mental impairment, they are not necessarily excluded from voting.

Legislation regarding the voting rights of the mentally ill varies from country to country. In certain states of America, for example, the mentally ill lose voting rights although these laws are gradually being repealed (Burton, 1990). However, The Canadian Charter of Rights and Freedoms has given institutionalised psychiatric patients the right to vote since 1985 (Valentine \& Turner, 1989). In the UK people detained in hospital under Sections of the Mental Health Acts may vote if they are on the electoral roll. "Idiots" cannot vote, but "lunatics" may during lucid intervals. Clearly these restrictions need revision. Voluntary patients who are receiving continuing care on psychiatric wards must have made a written declaration without assistance, on a specified date, before they can be registered to vote.

For those patients who are entitled to vote there may still be restrictions on their freedom to do so. Of our non-voters, 23 who expressed a desire to vote had been in-patients for less than the 17 days necessary to arrange postal or proxy votes. These people had a mean Barthel score of 16.87 (s.d. 4.2) and 18 of them had relatives, but nevertheless they did not leave the hospital to vote. Even when it is possible to arrange a postal or proxy vote this requires awareness on the part of the patient, relatives or ward staff. At the time of the election there were no established hospital protocols to facilitate in-patient voting. In Australia, where voting is compulsory, wards are visited by "electoral visitors" who ensure that people are registered and are able to vote by post, proxy or at mobile polling booths. We did not compare our subjects with younger in-patients or with elderly people in the community who may be just as unlikely to vote as our hospital population. A community study of the voting behaviour of old people in the US has shown that increasing age and lower self-assessment of health status make elderly Caucasians less likely to vote (Bazargan et al, 1991).

\section{Conclusion}

In this study we have identified some of the diffculties that elderly hospital in-patients face in exercising their right to vote and would suggest that they should be able to vote in hospital if necessary. Hospitals should have specific protocols for enabling voting by all their patients. We also warn against holding sham elections on wards looking after psychotic patients.

\section{Acknowledgements}

We are grateful to the patients, their relatives and the nursing staff on the wards for their assistance with data collection.

\section{References}

Bazargan, M., Kang, T. S. \& Bazargan, S. (1991) A multivariate analysis of elderly african americans and caucasians voting behaviour; how do social, health, psychological and political variables effect their voting? International Journal of Aging and Human Development. 32, 181-198.

BURTON, V. S. Jr. (1990) The consequences of official labels: A research note on rights lost by the mentally ill, mentally incompetent and convicted felons. Community Mental Health Journal, 26, 267-276.

Hodkinson, H. M. (1972) Evaluation of a mental test score for assessment of mental impairment in the elderly. Age and Ageing, 1, 233-238.

Mahony, F. I. \& Barthel, D. W. (1965) Functional evaluation: the Barthel Index. Maryland State Medical Journal, 14, 61-65.

VAlentine, M. B. \& TuRner, T. (1989) Political awareness of psychiatric patients. Canadian Medical Association Journal, 140, 498. 